\title{
MICROSTRUCTURE AND PROPERTIES OF DIRECT-AGED ALLOY 625
}

\author{
M. G. Burke, W. J. Mills and R. Bajaj \\ Bettis Atomic Power Laboratory \\ Bechtel Bettis, Inc. \\ West Mifflin, PA 15122
}

\begin{abstract}
The properties and microstructure of Alloy 625 are highly sensitive to heat treatment. This alloy is generally used in an annealed condition, although Alloy 625 is a precipitationhardenable material. To increase the strength, aging treatments are used to promote precipitation of fine disc-like $\mathrm{DO}_{22}$-ordered $\gamma^{\prime \prime}$ precipitates throughout the $\gamma$ matrix. The formation of these strengthening precipitates can also be accompanied by the precipitation of intergranular carbides and $\mathrm{Ni}_{3} \mathrm{Nb}(\delta)$ precipitates. The presence of these phases (carbides and $\delta$ ) has been reported to negatively affect the behavior of Alloy 625. In the direct aged (DA) condition, Alloy 625 possesses high strength, high ductility and good corrosion resistance. This paper presents the results of a microstructural characterization study using optical microscopy, scanning electron microscopy, analytical electron microscopy (including STEM-EDS microanalysis) and Auger electron spectroscopy. The mechanical and environmental cracking properties of DA-A625 are also described.
\end{abstract}

\section{Introduction}

Alloy 625, with its elevated $\mathrm{Cr}$ and Mo contents, is an attractive alloy for applications requiring good corrosion resistance. Although this material is commonly used in the annealed condition, it can be precipitation-hardened due to the high $\mathrm{Nb}$ and $\mathrm{Ti}$ contents. Aging at intermediate temperatures, approximately 650 to $700^{\circ} \mathrm{C}$, causes $\gamma^{\prime \prime}$ precipitation throughout the matrix which increases the yield strength above $750 \mathrm{MPa}$. In the direct-aged (DA) condition (ie, hot-rolled and aged at $663^{\circ} \mathrm{C}$ for 80 hours), its strength is comparable to that for high strength Ni-base alloys, and its environmental cracking resistance in low and high temperature water is excellent. Moreover, Alloy 625 is immune to irradiation-assisted stress corrosion cracking, unlike Alloy X-750 which experiences a large degradation in SCC resistance after irradiation. ${ }^{(1-3)}$

In this study, detailed microstructural characterization of DA Alloy 625 was performed using optical light microscopy, scanning electron microscopy, analytical electron microscopy (including STEM-EDS microanalysis), and Auger electron spectroscopy (AES). 
Differences in microstructure are correlated with variability in environmental cracking resistance.

\section{Experimental Techniques}

Material

The Alloy 625 heats used in this study were vacuum-induction melted and vacuum-arc remelted (VIM-VAR), and then hot worked. After hot working, the materials were direct aged (with no solution anneal) at $663^{\circ} \mathrm{C}$ for $80 \mathrm{~h}$. The compositions of materials used in this investigation are listed in Table 1; heat designations are consistent with those in References (1) and (2). All heats contained $<0.001 \mathrm{wt} . \% \mathrm{~S}$.

Table 1. Alloy 625 Composition (wt.\%)

\begin{tabular}{|c|c|c|c|c|c|c|c|c|c|c|c|}
\hline Heat & $\mathbf{C}$ & $\mathbf{C r}$ & $\mathbf{N i}$ & $\mathbf{F e}$ & $\mathbf{M o}$ & $\mathbf{N b}$ & $\mathbf{T i}$ & $\mathbf{A l}$ & $\mathbf{S i}$ & $\mathbf{P}$ & $\mathbf{B}$ \\
\hline D2 & 0.022 & 22.0 & 60.0 & 4.4 & 9.0 & 3.53 & 0.27 & 0.26 & 0.10 & 0.008 & 0.001 \\
\hline D11 & 0.026 & 21.9 & 61.0 & 3.68 & 9.0 & 3.52 & 0.29 & 0.25 & 0.12 & 0.007 & 0.001 \\
\hline D1 & 0.039 & 21.8 & 61.0 & 3.65 & 9.0 & 3.47 & 0.25 & 0.25 & 0.06 & 0.006 & 0.001 \\
\hline B3 & 0.042 & 21.8 & 62.5 & 2.31 & 8.8 & 3.91 & 0.28 & 0.28 & 0.05 & 0.003 & 0.002 \\
\hline A12 & 0.033 & 20.6 & 62.4 & 4.15 & 8.5 & 3.6 & 0.3 & 0.31 & 0.01 & 0.006 & 0.002 \\
\hline
\end{tabular}

Rising load properties obtained using precracked three-point bend bars that were tested in air and $93^{\circ} \mathrm{C}$ argon-sparged water are provided in Table 2. Key properties in this test are the stress intensity factor at maximum load $\left(\mathrm{K}_{\mathrm{Pmax}}\right)$ and the time required to go from maximum load to one-half maximum load $\left(\mathrm{t}_{1 / 2 \mathrm{Pmax}}\right)$. It is seen that all of the heats, except Heat D2, exhibit exceptionally high resistance to environmental cracking in low temperature water. In water, $\mathrm{K}_{\mathrm{Pmax}}$ values range from 98 to $110 \mathrm{MPa} \vee \mathrm{m}$ and $\mathrm{t}_{1 / 2 \mathrm{Pmax}}$ values range from 24 to 49 minutes. Heat $\mathrm{D}$ exhibits modest cracking resistance with the lowest properties occurring near the center of the bar. In fact, specimens taken near center of the bar exhibited a mean $t_{1 / 2 \mathrm{Pmax}}$ of only 11 minutes and significant intergranular cracking when tested in water. Fracture surfaces of sister specimens tested in air displayed limited intergranular fracture. No other specimens from " $A$ " or " $D$ " heats exhibited any evidence of intergranular cracking in either air or water. It is noted that coarse-grained regions of Heat B3 showed evidence of intergranular cracking in tensile tests, as discussed later.

\section{Microstructural Characterization}

Specimens for Light Optical Microscopy were metallographically polished and etched in $2 \% \mathrm{Br}-\mathrm{CH}_{3} \mathrm{OH}$ prior to examination. These specimens and fractured tensile samples were also evaluated in a JEOL 6100 Scanning Electron Microscope equipped with a conventional energy dispersive $\mathrm{x}$-ray spectrometer (EDS) system. Detailed microstructural analysis was performed using Analytical Electron Microscopy (AEM). Electron-transparent thin-foil specimens were prepared for AEM using a conventional jet electropolishing technique in an electrolyte of $20 \% \mathrm{HClO}_{4}-80 \% \mathrm{CH}_{3} \mathrm{OH}$ at $-35^{\circ} \mathrm{C}$. In addition, carbon extraction replica specimens were prepared to permit the characterization of carbides and carbonitrides in the material. Both thin-foil and carbon extraction replica specimens were subsequently 
examined in a Philips CM12 Analytical Electron Microscope equipped with a Link Analytical LZ5 energy dispersive x-ray spectrometer and AN10/85S analyzer.

In addition to AEM characterization, the extent of segregation was evaluated using Auger Electron Spectroscopy (AES). The AES analyses were performed twice, on two different Physical Electronics Phi Scanning Auger Microscopes (SAM). Prior to AES evaluation, notched cantilever bend specimens were hydrogen-precharged in a reaction chamber containing tantalum hydride. The reaction chamber was held at the aging temperature of $663^{\circ} \mathrm{C}$ for 1.5 hours to dissociate the hydride and produce a high pressure $\mathrm{H}_{2}$ gas for specimen charging. Hydrogen-precharged specimens were then inserted into the SAM chamber where they were fractured in situ by a slow bending technique to promote intergranular fracture. Fracture surfaces contained significant amounts of both intergranular and transgranular fracture. The transgranular regions had a faceted appearance suggesting that hydrogen promotes planar slip and localized cracking along planar slip bands. Facets often extend across a single grain, such that their appearance resembles an intergranular morphology. Therefore, care was taken to exclude transgranular facets when characterizing grain boundary chemistry. Ten intergranular locations on each specimen were analyzed. Analysis of $\mathrm{P}, \mathrm{S}$ and $\mathrm{B}$ was compromised due to interference with strong elemental peaks for $\mathrm{Mo}$ and $\mathrm{Nb}$. Sulfur and $\mathrm{P}$ concentrations were corrected based on sputtering analysis for these elements and Mo, the primary interfering element. The correction method used a reference piece of Alloy 625 with a known bulk composition that was cleaned by sputtering and then analyzed by AES to develop sensitivity factors specific to Alloy 625 . No meaningful AES data were obtained for $\mathrm{B}$ due to severe $\mathrm{Nb}$ interference.

Table 2. Rising Load Properties for Alloy 625 Heats

\begin{tabular}{|c|c|c|c|c|c|c|}
\hline \multirow{2}{*}{ Heat } & \multirow{2}{*}{$\begin{array}{c}\text { Bar } \\
\text { Diam. } \\
\end{array}$} & \multirow{2}{*}{ Location } & \multicolumn{2}{|c|}{$\mathbf{K}_{\text {Pmax }}(\mathbf{M P a} \sqrt{\mathbf{m}})$} & \multicolumn{2}{c|}{$\mathbf{t}_{\mathbf{1} \text { /2 } \max }(\mathbf{m i n})$} \\
\cline { 4 - 7 } & & Air & Water & Air & Water \\
\hline D2 & 140 & $1 / 4$ Radius & $86 \pm 3$ & $77 \pm 3$ & 40 & $11 \pm 3$ \\
\hline D2 & 140 & $1 / 2$ Radius & $89 \pm 3$ & $82 \pm 3$ & 39 & $20 \pm 10$ \\
\hline D11 & 51 & - & $101 \pm 2$ & $98 \pm 2$ & 50 & $49 \pm 3$ \\
\hline D1 & 51 & - & $107 \pm 3$ & $110 \pm 3$ & - & $24 \pm 3$ \\
\hline A12 & 76 & - & $111 \pm 8$ & $108 \pm$ & $39 \pm 5$ & $28 \pm 5$ \\
\hline
\end{tabular}

\section{Mechanical Testing}

Flat tensile specimens $(0.125 \mathrm{~mm}$ thick $X 2.5 \mathrm{~mm}$ gage width $X 19 \mathrm{~mm}$ long) were fabricated from fully heat-treated $\sim 50 \mathrm{~mm}$ diameter bars such that the gage length was parallel to the longitudinal axis of the bar. Tensile testing was conducted at $65^{\circ} \mathrm{C}$ and $288^{\circ} \mathrm{C}$ representative of low-temperature crack propagation and high-temperature SCC regions, respectively. All test were conducted in an MTS servohydraulic machine at a strain rate of 2.2.X $10^{-5} \mathrm{~s}^{-1}$. The load-stroke data were analyzed to calculate $0.2 \%$ offset yield stress, ultimate tensile stress, uniform elongation, and necking strain (total elongation - uniform elongation), true strain, engineering fracture stress, and true fracture stress in a conventional way. Stress- strain behavior was analyzed as:

$$
\sigma_{\mathrm{t}}=\mathrm{K} \varepsilon^{\mathrm{n}}
$$

where: $\mathrm{K}$ is a constant, $\sigma_{\mathrm{t}}$ is true stress, and $\varepsilon$ is the true plastic strain defined as:

$$
\varepsilon=\varepsilon_{\mathrm{t}}-\sigma_{\mathrm{t}} / \mathrm{E}, \text { and }
$$




$$
\mathrm{n}=\mathrm{d}\left(\ln \sigma_{\mathrm{t}}\right) / \mathrm{d}(\ln \varepsilon)
$$

where: $\varepsilon_{\mathrm{t}}$ is true strain $\left(\varepsilon_{\mathrm{t}}=\ln (1+\mathrm{e})\right.$, where $\mathrm{e}$ is engineering strain) and $\mathrm{E}$ is the elastic modulus.

Like other Ni-base alloys, DA-625 exhibits a bilinear log (true stress) vs. log (true strain) relationship. At low strains the strain hardening exponent is low while at high strains the exponent is high. Therefore both exponents were calculated. " $n_{1}$ " corresponds to strains from $0.5 \%$ to $3 \%$ and " $n_{2}$ " corresponds to strains from $5 \%$ to approximately the uniform elongation.

\section{Results}

\section{Microstructural Characterization: LOM and AEM}

The DA materials were characterized by a nonuniform grain size (from 10 to $\sim 50 \mu \mathrm{m}$ ) and a distribution of coarse blocky inclusions. In the case of the $140-\mathrm{mm}$ diameter forged bar, the central region consisted of coarse grains whereas the outer region (and also the smaller diameter bars) was characterized by a finer grain structure. The coarse grain size is atypical of Alloy 625 and is due to insufficient deformation of the interior of the large diameter bar, which precluded dynamic recrystallization during hot working. Intergranular carbide precipitation appeared to vary significantly throughout the microstructure. SEM-EDS evaluation indicated that these inclusions were $\mathrm{Ti}-\mathrm{Nb}$-rich carbonitrides.

All heats of DA-625 exhibited similar microstructures. AEM characterization revealed the presence of a fairly uniform distribution of body centered tetragonal $\mathrm{D}_{22}$-ordered $\gamma^{\prime \prime}$ precipitates throughout the $\gamma$ matrix. These disc-shaped precipitates were approximately 15 $\mathrm{nm}$ in diameter and $\sim 4 \mathrm{~nm}$ in thickness, and exhibited the expected orientation relationship with the face-centered cubic matrix: $(100)_{\gamma^{\prime \prime}} / /\{100\}$ matrix and $[010]_{\gamma^{\prime \prime}} / /<010>$ matrix. Although precipitation within the matrix was fairly uniform, pre-exisiting dislocations (associated with hot working) acted as sites for the preferential precipitation of the $\gamma^{\prime \prime}$ precipitates. Figure 1 contains examples of the extent of intragranular precipitation observed in the DA specimens. These particular dark-field transmission electron micrographs were obtained from [001]-oriented foils, so that two of the three variants of the $\gamma^{\prime \prime}$ precipitates could be imaged simultaneously.

Some local variations in the extent of $\gamma^{\prime \prime}$ precipitation were noted in the vicinity of the coarse $\mathrm{Ti} / \mathrm{Nb}$ carbonitride inclusions and near $\mathrm{Nb}$ - $\mathrm{Ti}$ film-like carbonitrides, where the depletion of $\mathrm{Ti}$ and $\mathrm{Nb}$ associated with the formation of the inclusions and precipitates resulted in $\gamma^{\prime \prime}$ precipitate-free zones (PFZ), Figure $1 \mathrm{~b}$. Composition profiles measured across a $\gamma^{\prime \prime}$ PFZ using STEM-EDS microanalysis showed that the $\mathrm{Ti}$ and $\mathrm{Nb}$ levels within the PFZ were reduced by $\sim 50 \%$ from the bulk levels. Narrow PFZs were also observed in the vicinity of Nb-enriched $\mathrm{DO}_{\mathrm{a}}$-ordered $\delta$ phase precipitates. Very few needle-like $\delta$ precipitates were detected in these materials.

The extent of intergranular carbide precipitation varied from heat to heat. Electron diffraction and scanning transmission electron microscopy - energy dispersive $\mathrm{x}$-ray spectroscopy (STEM-EDS) microanalysis confirmed that the fine intergranular carbides detected were primarily $\mathrm{M}_{23} \mathrm{C}_{6}$ with a few $\mathrm{M}_{6} \mathrm{C}$ and $\mathrm{M}_{7} \mathrm{C}_{3}$ precipitates. Figure 2 shows examples of the intergranular carbide precipitation in the Direct-Aged alloy. STEM-EDS microanalysis of carbon extraction replica specimens provided composition data (excluding $\mathrm{C}$ and $\mathrm{N}$ ) for the carbides, and it listed in Table 3 . In addition to these $\mathrm{Cr}$-enriched carbides, numerous $\mathrm{Nb} / \mathrm{Ti}$-rich film-like precipitates were detected in heat D2, Figure 3. 


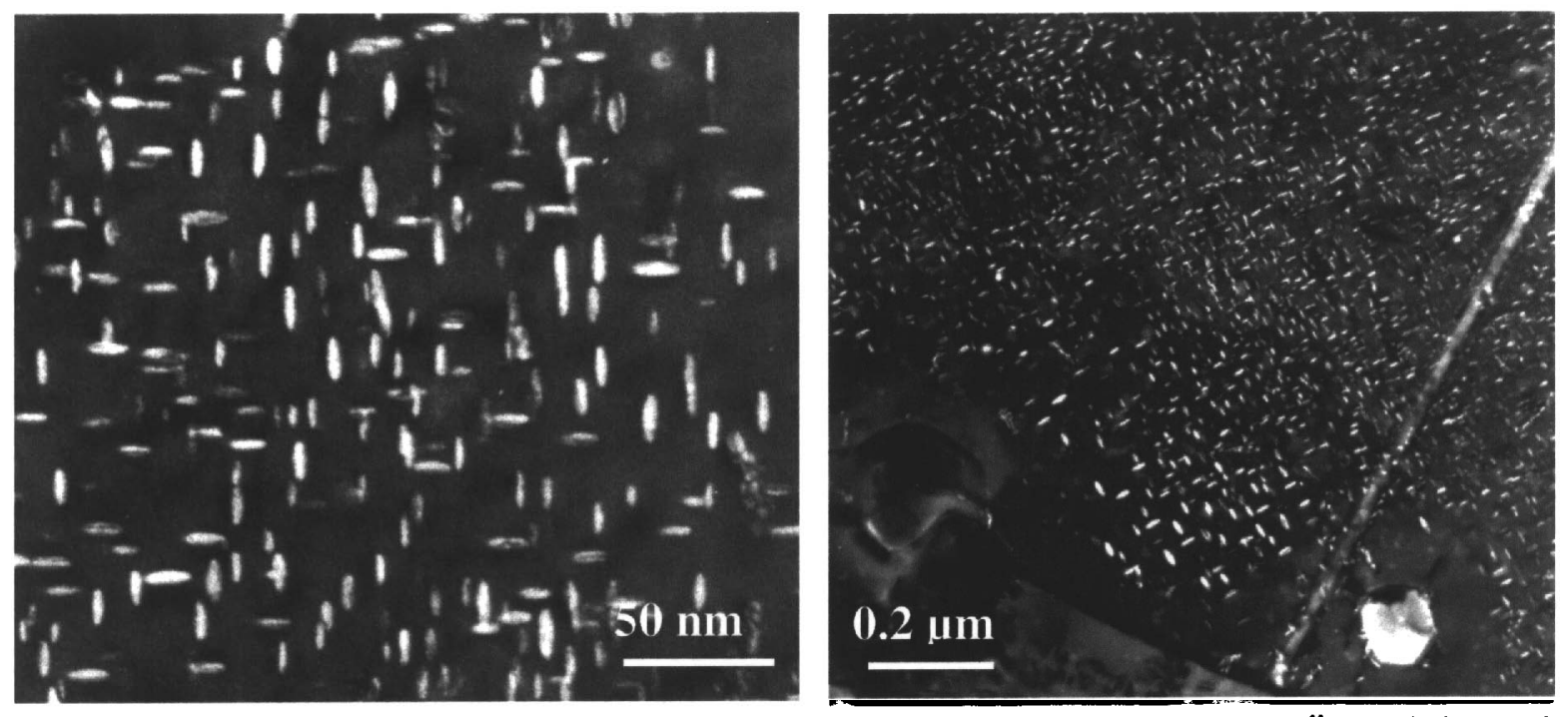

Figure 1. [001]-oriented dark-field TEM images showing 2 variants of the $\gamma^{\prime}$ precipitates in DA-625. Note the variation in size and extent of precipitation near denuded zones.
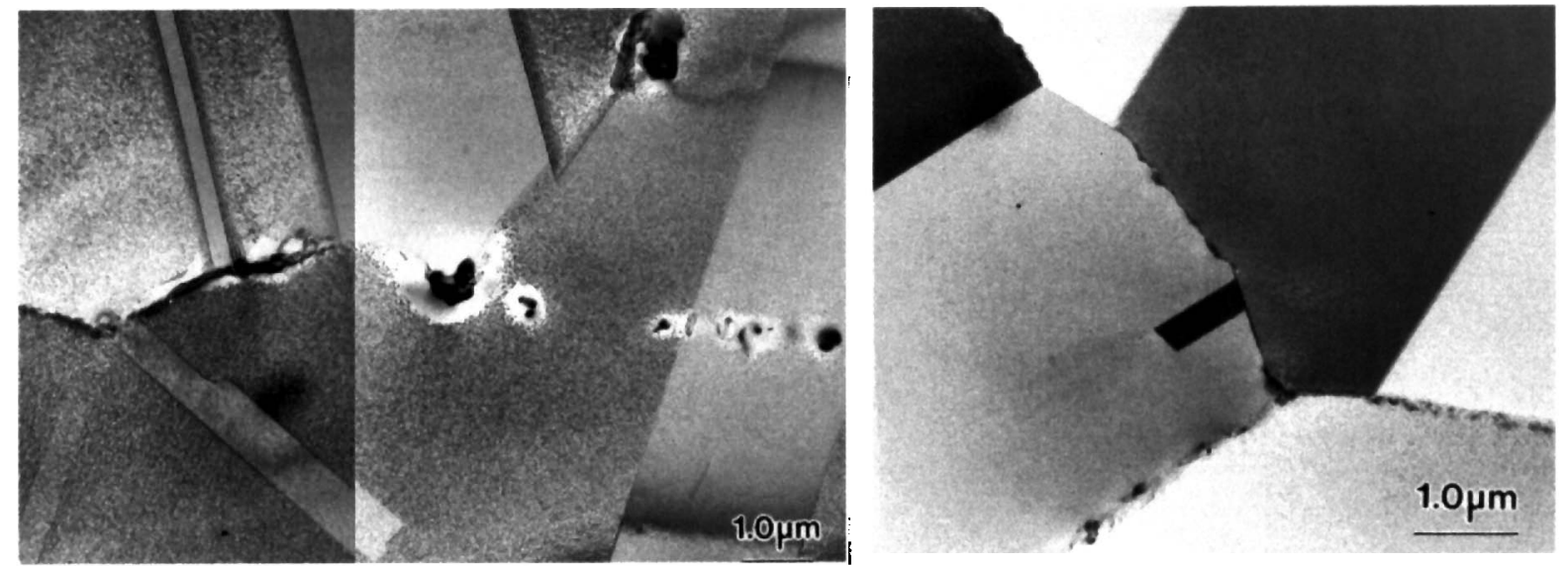

Figure 2. Transmission electron micrographs showing the extent of intergranular carbide (primarily $\mathrm{M}_{23} \mathrm{C}_{6}$ ) precipitation in the DA alloys. Note the presence of $\gamma^{\prime \prime}$ PFZs around the $\mathrm{Nb}, \mathrm{Ti}(\mathrm{C}, \mathrm{N})$ inclusions and intergranular precipitates.
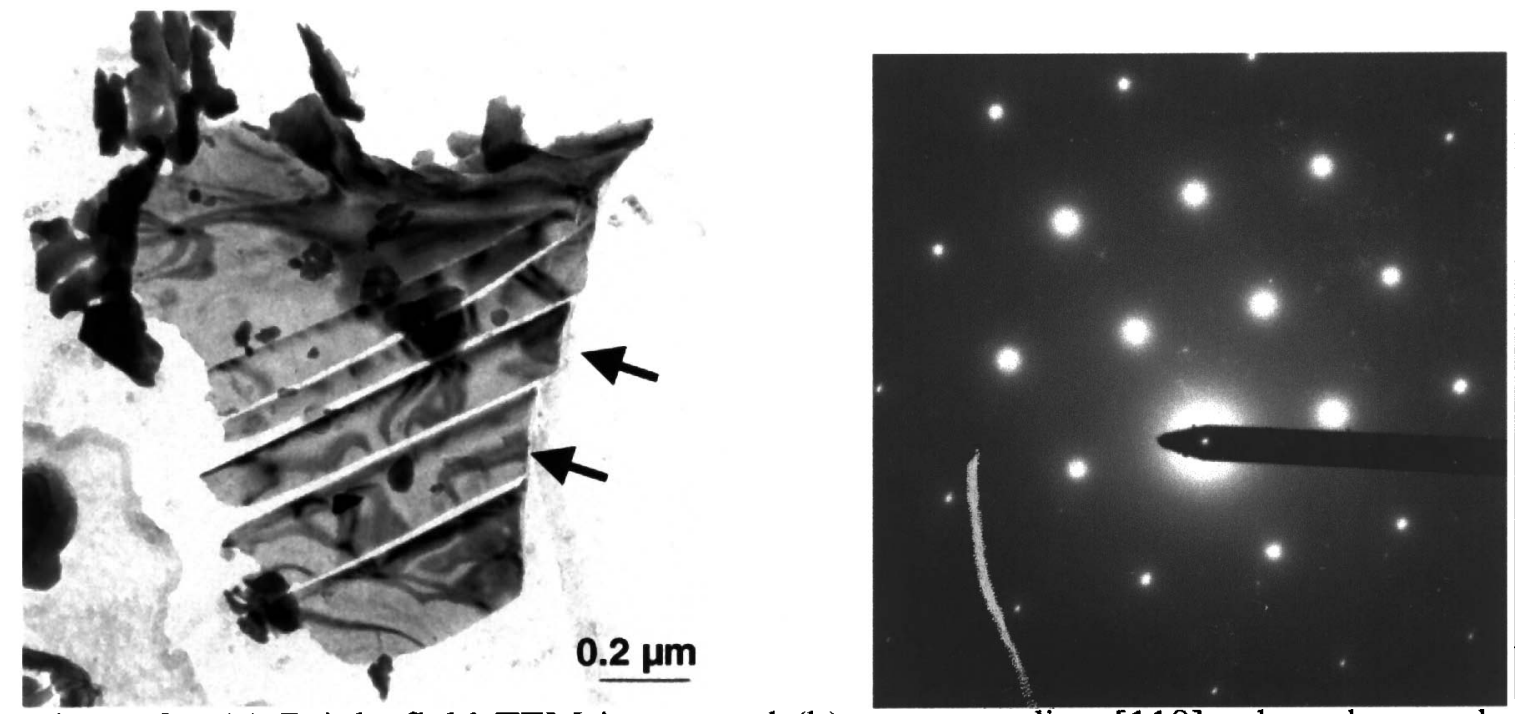

Figure 3. (a) Bright-field TEM image and (b) corresponding [110] selected area electron diffraction pattern of the thin $\mathrm{Nb}, \mathrm{Ti}(\mathrm{CN})$ film-like precipitate (arrowed) detected in heat D2. In addition to the $\mathrm{Nb}, \mathrm{Ti}(\mathrm{CN})$ films, discrete $\mathrm{M}_{23} \mathrm{C}_{6}$ carbides were also identified at grain boundaries (faint reflections for $\mathrm{M}_{23} \mathrm{C}_{6}$ ) are visible in (b). 
Table 3. STEM-EDS Microanalysis Data (wt.\%) for Precipitate Characterization

\begin{tabular}{|c|c|c|c|c|c|c|c|}
\hline Precipitate & $\mathbf{C r}$ & $\mathbf{N i}$ & $\mathbf{F e}$ & $\mathbf{M o}$ & $\mathbf{N b}$ & $\mathbf{T i}$ & $\mathbf{A l}$ \\
\hline $\mathbf{M}_{\mathbf{2 3}} \mathbf{C}_{\mathbf{6}}$ & 80.7 & 5.7 & 0.2 & 13.2 & -- & -- & 0.3 \\
\hline $\mathbf{M}_{\mathbf{6}} \mathbf{C}$ & 33.6 & 23.9 & 0.7 & 32.7 & 8.2 & 0.2 & 0.8 \\
\hline \multirow{3}{*}{$\mathbf{M}(\mathbf{C N})$} & 7.0 & 1.3 & 0.1 & 2.7 & 36.5 & 52.6 & -- \\
\cline { 2 - 8 } & 3.7 & 0.4 & 0.3 & 10.8 & 76.6 & 8.6 & -- \\
\hline
\end{tabular}

Although numerous grain boundaries were free of carbides, detailed TEM examination showed that these carbide-free grain boundaries contained fine $\gamma^{\prime \prime}$ precipitates, Figure 4.

Microchemical Characterization by Auger Electron Spectroscopy (AES):

Grain boundary and bulk compositions for the Alloy 625 heats are provided in Table 4 . Heats D2 (center and surface) and D11 were analyzed twice: on two different Scanning Auger Microscopes. Carbon was not included in the first analysis because $\mathrm{C}$ deposition from the electron beam typically produces artificially high measurements. Nevertheless, the second analysis shows important differences in grain boundary $\mathrm{C}$ as a function of location within the large diameter bar. Grain boundary compositions obtained from the two analyses are in general agreement. The modest differences in $\mathrm{Cr}$, $\mathrm{Fe}$ and $\mathrm{Mo}$ are expected when two different microscopes and analysis methods are used. The large difference in grain boundary $\mathrm{Ni}$ for the center of Heat D2 is associated with variations in analysis methods (i.e., including or excluding $\mathrm{C}$ in the analysis) coupled with an unusually high variability in $\mathrm{Ni}$ concentration. The standard deviation on $\mathrm{Ni}$ in the center of Heat D2 $(9.2 \mathrm{a} / \mathrm{o})$ is triple that for other locations in this heat and other heats.

Inspection of the AES data in Table 4 reveals the following:

1. Equilibrium segregation of $\mathbf{P}$ is indicated for all heats, with the coarse-grained center region of Heat D2 exhibiting the highest concentration. Levels for the remaining materials are lower and rather uniform.

2. As expected, grain boundary S levels are very low as Mo tends to retard segregation. ${ }^{(5)}$ Proposed mechanisms for suppressing segregation include: scavenging impurity elements by stable compound formation ${ }^{(5-7)}$ and increasing the activation energy for impurity element diffusion. ${ }^{(8)}$

3. Niobium levels are highest in grain boundaries located in the center section of Heat D2. For the other locations in Heat D2 and the other heats, grain boundary Nb levels are slightly less than the bulk composition, because $\mathrm{Nb}$ is tied up in carbonitride inclusions.

4. Grain boundary $\mathrm{Ti}$ levels in the center section of Heat D2 are slightly enriched. Titanium levels for the other materials are very near bulk concentrations.

5. Grain boundary $\mathrm{Cr}$ levels are uniform from heat to heat and tend to be slightly lower than the bulk concentration.

6. Although $\mathrm{C}$ levels in Table 4 are high due to carbon deposition, it is apparent that grain boundary $\mathrm{C}$ in the center section of Heat $\mathrm{D} 2$ is much higher than that in other materials.

The AES findings show that the coarse-grained region in the center section of Heat D2 exhibits the highest levels of $\mathrm{P}$ segregation. For this heat, average $\mathrm{P}$ levels are 2.5 and 2.9 $\mathrm{a} / \mathrm{o}$ in the center location, $1.5 \mathrm{a} / \mathrm{o}$ at the mid-radius location, and 1.5 and $1.7 \mathrm{a} / \mathrm{o}$ at the 
surface. Average $P$ levels for the other heats range from 1.3 to $1.9 \mathrm{a} / \mathrm{o}$. The coarse grain size in the center of the large diameter bar is probably responsible for the increased $\mathrm{P}$ segregation, because there is less grain boundary area over which the $\mathrm{P}$ is distributed.

AES results also demonstrate that the center section of Heat D2 exhibits higher $\mathrm{C}$ and $\mathrm{Nb}$ and slightly higher $\mathrm{Ti}$. The combination of high $\mathrm{C}$ and $\mathrm{Nb}$ indicates that $\mathrm{Nb}$-rich carbides or carbonitrides are present on many grain boundaries at this location. The slightly higher Ti levels suggest that there is some Ti substitution for $\mathrm{Nb}$. These findings are consistent with the STEM-EDS analysis that revealed the presence of a grain boundary film of ( $\mathrm{Nb}, \mathrm{Ti}) \mathrm{C}, \mathrm{N}$ in the center of the large diameter bar.

Elemental distribution mapping of Heat D2 shows evidence of $\mathrm{MgS}$, but these particles are not confined to any particular location within the bar. Similar sulfides are also present in Heat D11. Because MgS are present in materials with inferior and superior environmental cracking resistance, there appears to be no correlation between these sparsely distributed sulfides and cracking performance.

\section{Mechanical Properties and Fractography}

Two heats of DA-A625 (Heats B3 and D1) were tensile tested at $65^{\circ} \mathrm{C}$ and an additional heat (A12) were tested at a temperature of $288^{\circ} \mathrm{C}$. Table 5 shows the results of tensile testing and lists yield stress $\left(\sigma_{Y S}\right)$, ultimate tensile stress $\left(\sigma_{\mathrm{UTS}}\right), \%$ uniform elongation, $\%$ total elongation, $\%$ necking strain, engineering fracture stress $\left(\sigma_{\text {frac }}\right)$, true $\sigma_{\text {UTS }}$ and strain hardening exponents for all tests.

In the DA condition, A625 is a high-strength material with $\sigma_{Y S}$ above $720 \mathrm{MPa}$ and $\sigma_{\text {UTS }}$ above $1020 \mathrm{MPa}$ at $65^{\circ} \mathrm{C}$ and above $680 \mathrm{MPa}$ and $1000 \mathrm{MPa}$, respectively at $288^{\circ} \mathrm{C}$. It also has a high ductility with uniform elongation above $25 \%$ and total elongation above $28 \%$ at both temperatures. Figure $4 \mathrm{a}$ shows the $\sigma_{Y S}$ and $\sigma_{\text {UTS }}$ and Figure $4 \mathrm{~b}$ shows the ductility for all alloys. The strain hardening exponent $n_{1}$ was between 0.05 and 0.06 for all heats. The $n_{2}$ exponent ranged from 0.19 to 0.23 .

The two heats, B3 and D1 showed similar properties at $65^{\circ} \mathrm{C}$ and $288^{\circ} \mathrm{C}$. Heat $\mathrm{A} 12$ showed higher strength and lower ductility than the other two heats at a test temperature of $288^{\circ} \mathrm{C}$.

The SEM examination of the fracture surfaces of samples of Heats D1 and A12, tested at either temperature, showed that the failure occurred by a transgranular dimple rupture process with no evidence of intergranular fracture. The dimples nucleated at the matrix inclusions with larger inclusions nucleating larger dimples. Figure 5 contains typical fractographs of a sample of Heat A12. The fracture behavior of Heat B3 was different from that of the other two heats. This heat had a large average grain size and also exhibited a larger grain size variation from one region of the bar stock to another. In this heat, the fracture surface showed a mixed transgranular/intergranular mode of fracture with secondary cracking, Figure 6. The coarse-grained areas exhibited intergranular fracture with smaller dimples on the grain boundary facets. The fine-grained regions failed transgranularly by a dimple rupture process with ill-defined dimples and void-sheet formation. The intergranular cracks showed extensive slip activity with parallel and intersecting slip traces and fine dimples as shown in Figure 6(b). The fracture behavior of this heat was similar at the two test temperatures. 


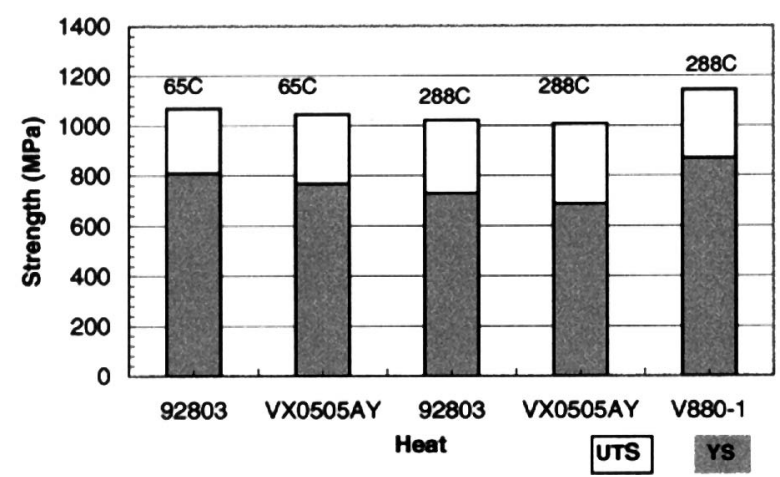

(a)

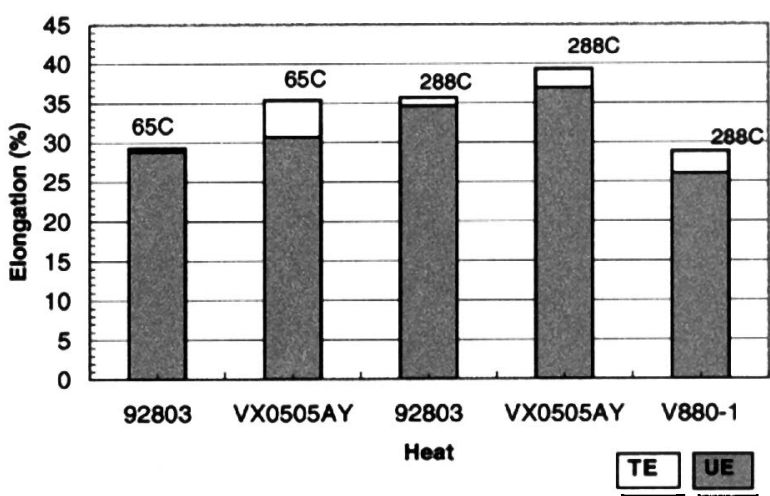

(b)

Figure 4. Mechanical properties of DA-A625. (a) Yield Stress ( $\sigma_{\mathrm{YS}}$ ) and Ultimate Tensile Stress $\left(\sigma_{\mathrm{UTS}}\right)$ and (b) \% Uniform Elongation and \% Total Elongation
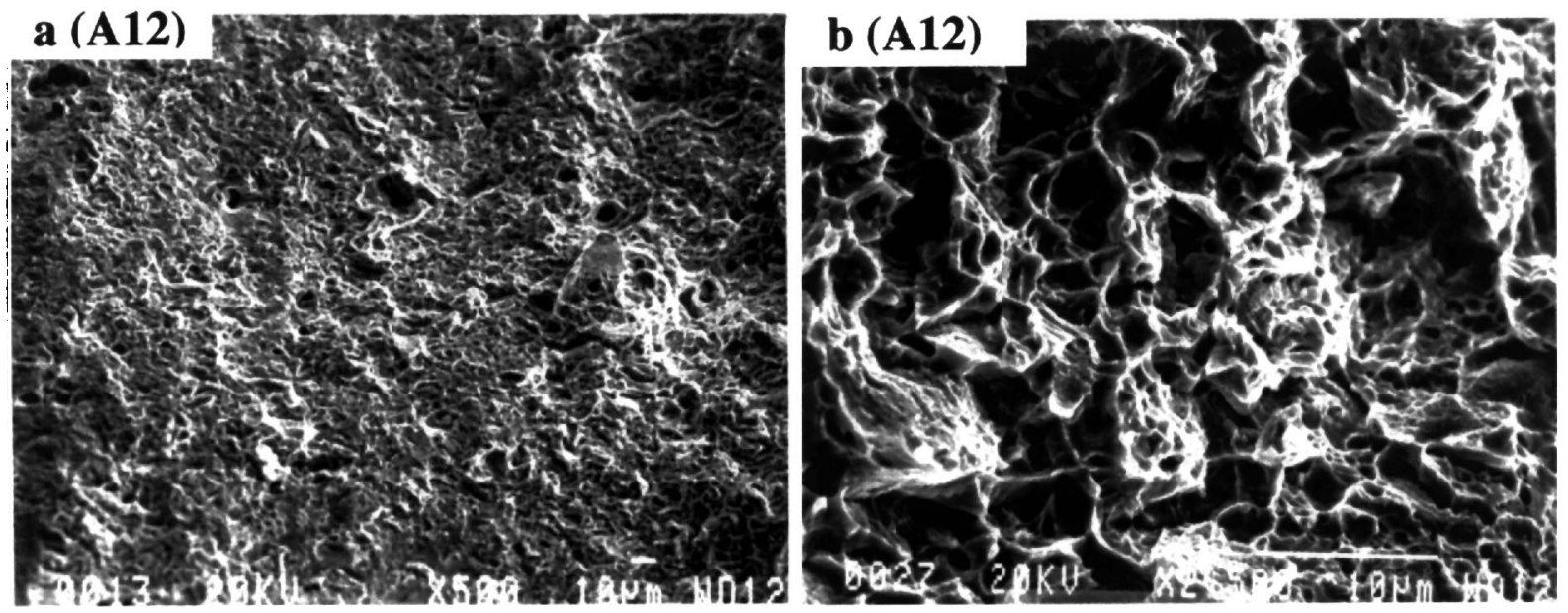

Figure 5. SEM fractographs of DA-A625 Heat A12 showing a transgranular dimpled fracture morphology.
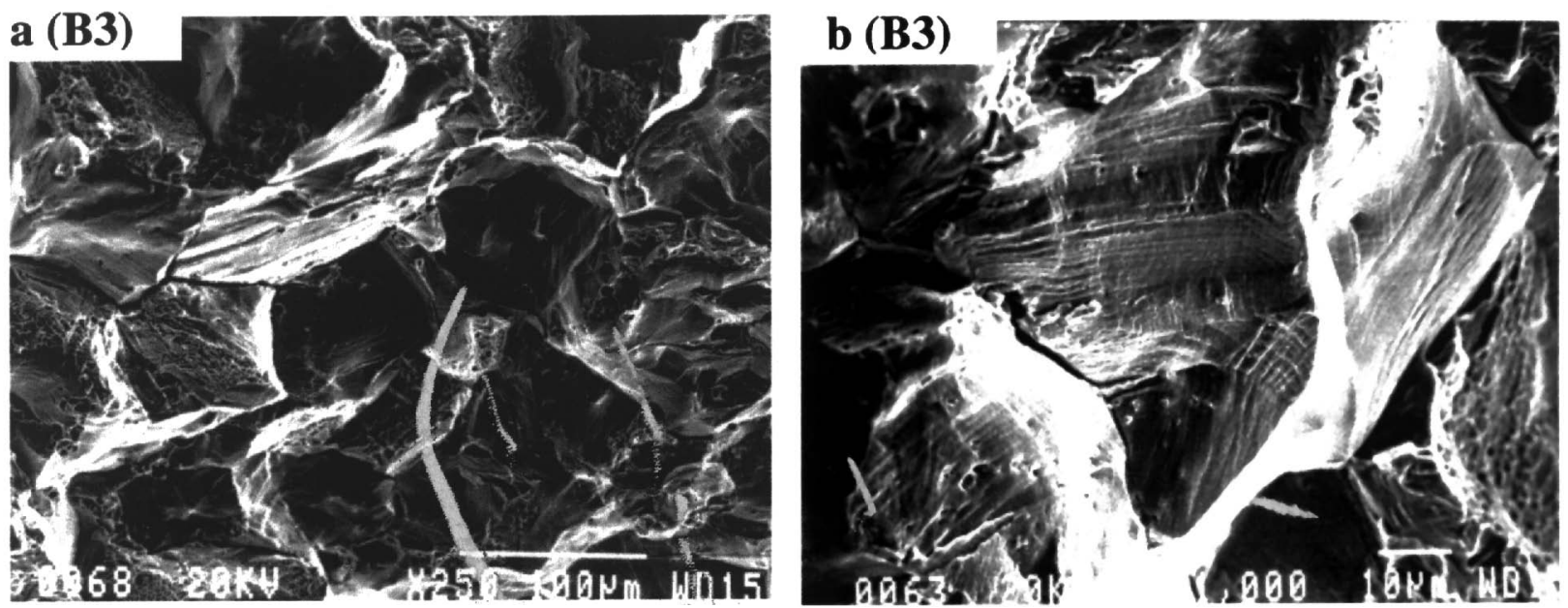

Figure 6. SEM fractographs of DA-A625 Heat B3 showing an intergranular fracture morphology and secondary cracking. 
Table 4. Bulk Composition and Average AES Grain Boundary Composition (at.\%)

\begin{tabular}{|c|c|c|c|c|c|c|c|c|c|}
\hline & $\mathbf{P}$ & $\mathbf{S}$ & $\mathrm{C}$ & $\mathbf{N b}$ & Ti & $\mathrm{Cr}$ & $\mathrm{Fe}$ & $\mathrm{Ni}$ & Mo \\
\hline & \multicolumn{9}{|c|}{ Bulk Composition } \\
\hline D2 & 0.015 & 0.002 & 0.11 & 2.26 & 0.34 & 25.1 & 4.68 & 60.79 & 5.58 \\
\hline D11 & 0.013 & 0.002 & 0.13 & 2.25 & .036 & 25.0 & 3.92 & 62.79 & 5.59 \\
\hline \multirow[t]{2}{*}{ B3 } & 0.006 & 0.002 & 0.21 & 2.50 & .035 & 24.9 & 2.46 & 63.32 & 5.47 \\
\hline & \multicolumn{9}{|c|}{ Average $^{+}$AES Grain Boundary Composition ${ }^{\ddagger}$} \\
\hline \multirow{2}{*}{ D2 Center ${ }^{*}$} & 2.5 & 0.0 & - & 3.0 & 0.5 & 22.7 & 4.3 & 61.0 & 6.0 \\
\hline & 2.9 & $0.1^{\ddagger}$ & 16.7 & 3.1 & 0.6 & 18.3 & 3.1 & 50.8 & 4.4 \\
\hline D2Mid-Radius & 1.5 & $0.1^{\ddagger}$ & 5.4 & 2.0 & 0.5 & 17.0 & 3.7 & 67.1 & 3.1 \\
\hline \multirow{2}{*}{ D2 Surface ${ }^{*}$} & 1.7 & 0.0 & - & 1.3 & 0.4 & 24.0 & 4.3 & 61.7 & 5.7 \\
\hline & 1.5 & $0.4^{\ddagger}$ & 4.3 & 1.7 & 0.5 & 19.2 & 3.8 & 65.8 & 3.2 \\
\hline \multirow[t]{2}{*}{ D11 } & 1.6 & 0.0 & - & 1.8 & 0.34 & 25.2 & 3.7 & 61.0 & 6.0 \\
\hline & 1.9 & $0.1^{\ddagger}$ & 6.2 & 1.7 & 0.5 & 20.8 & 3.0 & 61.5 & 4.3 \\
\hline $\mathrm{D} 2$ & 1.3 & 0.0 & - & 2.0 & 0.32 & 24.7 & 2.5 & 63.3 & 5.8 \\
\hline
\end{tabular}

${ }^{+}$Ten grain boundary facets were analyzed during each AES evaluation.

"Two evaluations on different Scanning Auger Microscopes were performed on Heats D2 and D11.

$\ddagger$ Note that values below 0.5 to $1 \mathrm{a} / \mathrm{o}$ are probably not significantly different from 0 .

Table 5. Results of Tensile Tests

\begin{tabular}{|c|c|c|c|c|c|c|c|c|c|c||}
\hline Heat & $\begin{array}{c}\mathrm{T} \\
\left({ }^{\circ} \mathrm{C}\right)\end{array}$ & $\begin{array}{c}\sigma_{\mathrm{YS}} \\
(\mathrm{MPa})\end{array}$ & $\begin{array}{c}\sigma_{\mathrm{UTS}} \\
(\mathrm{Mpa})\end{array}$ & $\begin{array}{c}\text { Uniform } \\
\text { Elong. } \\
(\%)\end{array}$ & $\begin{array}{c}\text { Total } \\
\text { Elong. } \\
(\%)\end{array}$ & $\begin{array}{c}\text { Necking } \\
\text { Strain } \\
(\%)\end{array}$ & $\begin{array}{c}\text { Eng. } \\
\sigma_{\text {frac }} \\
(\mathrm{MPa})\end{array}$ & $\begin{array}{c}\text { True } \\
\sigma_{\mathrm{UTS}} \\
(\mathrm{MPa})\end{array}$ & $\mathrm{n}_{1}$ & $\mathrm{n}_{2}$ \\
\hline \hline $\mathrm{B} 3$ & 65 & 808 & 1069 & 28.8 & 29.3 & 0.5 & 988 & 1379 & 0.05 & 0.21 \\
\hline $\mathrm{D} 1$ & 65 & 767 & 1045 & 30.7 & 35.4 & 4.7 & 829 & 1365 & 0.06 & 0.23 \\
\hline $\mathrm{B} 3$ & 288 & 729 & 1022 & 34.6 & 35.7 & 1.1 & 912 & 1373 & 0.05 & 0.24 \\
\hline $\mathrm{D} 1$ & 288 & 687 & 1008 & 36.9 & 39.3 & 2.4 & 924 & 1380 & 0.06 & 0.26 \\
\hline $\mathrm{A} 12$ & 288 & 870 & 1143 & 26 & 28.8 & 2.8 & 994 & 1440 & 0.06 & 0.19 \\
\hline
\end{tabular}

\section{Discussion}

The inferior environmental cracking resistance of the center section of the large diameter bar from Heat D2 appears to be associated with a combination of metallurgical factors including grain boundary $\mathrm{P}$ segregation, a coarse grain structure, and an intergranular film of $\mathrm{Nb}, \mathrm{Ti}(\mathrm{C}, \mathrm{N})$. The most likely candidates for embrittling this material are equilibrium segregation of $\mathrm{P}$ and a large grain size. As a hydrogen recombination poison, $\mathrm{P}$ enhances hydrogen absorption by retarding recombination of atomic hydrogen into molecular hydrogen, which cannot be absorbed by the metal. In addition, $\mathrm{P}$ reduces grain boundary cohesive strength of Ni-base alloys. In high-strength Ni-base Alloy X-750, grain boundary $\mathrm{P}$ concentrations have been correlated with cracking susceptibility in low temperature water. ${ }^{(4)}$ 
The coarse grain size can promote intergranular cracking because it causes planar slip that leads to high local stresses on grain boundaries. The importance of grain size is clearly demonstrated by the tension tests that showed intergranular cracking in the coarse-grained regions of Heat $\mathrm{B} 3$. The $\mathrm{P}$ segregation exhibited by this material is comparable to amounts observed in other heats that were immune to intergranular cracking. Therefore, the coarse grain structure alone can promote intergranular cracking.

Coarse intergranular precipitates and films can reduce the grain boundary cohesive strength and act as stress concentration sites. It is likely, therefore, that the intergranular precipitates also contributed to the degraded environmental properties exhibited by the center section of the $140-\mathrm{mm}$ diameter bar. While the thin film of $\mathrm{Nb}, \operatorname{Ti}(\mathrm{C}, \mathrm{N})$ may have contributed to the poor rising load performance, this precipitate morphology is observed in the outer regions of this bar which display improved cracking resistance. Hence, the thin intergranular film is not uniquely responsible for the degraded properties in the center of the bar.

\section{Conclusions}

Detailed characterization of the microstructure and grain boundary chemistry for DA Alloy 625 was performed to correlate microstructural features with mechanical properties and environmental cracking resistance. Key findings from this study are provided below:

Grain boundary segregation of $\mathrm{P}$ and a coarse grain size appear to be deleterious to the good inherent environmental cracking resistance of Alloy 625. The coarse grain structure, which results from inadequate working of the interior of large sections, promotes grain boundary segregation and fosters planar slip that produces large stress concentrations on grain boundaries

Although the $\mathrm{Nb}, \mathrm{Ti}(\mathrm{C}, \mathrm{N})$ film probably contributed to the inferior properties displayed by the coarse-grained material, it is not uniquely responsible for grain boundary separation because this feature is observed in regions that resist intergranular cracking.

\section{References}

1. W. J. Mills, M. R. Lebo, J. J. Kearns, R. C. Hoffman, J. J. Korinko, R. F. Luther and G. B. Sykes, 6th Intl. Symp. on Environmental Degradation of Materials in Nuclear Power Systems-Water Reactors, (TMS, 1993) p. 633

2. R. Bajaj, W. J. Mills, M. R. Lebo, B. Z. Hyatt and M. G. Burke, 7th Intl Symp. on Environmental Degradation of Materials in Nuclear Power Systems-Water Reactors, (NACE, Vol. 2, 1995) p. 1093.

3. R. Bajaj, W. J. Mills, B. F. Kammenzind and M. G. Burke, 9th Intl Symp. on Environmental Degradation of Materials in Nuclear Power Systems-Water Reactors, (TMS, 1999) p. 1069.

4. W. J. Mills, M. R. Lebo and J. J. Kearns, Met. Transactions, 30A (1999) p. 1579.

5. C. J. McMahon, Jr., Mat. Sci and Eng., 42 (1980) p. 215.

6. B. J. Schulz and C. J. McMahon, Jr., Temper Embrittlement of Alloy Steels, ASTM STP 499, (1972) p. 104.

7 C. J. Murza and C. J. McMahon, Jr., J. Eng. Mat. and Tech., 102 (1980) p. 369.

8. J. M. Capus, Temper Embrittlement in Steel, ASTM STP 407 (1968) p. 3. 